\title{
ALIENACIÓN Y COSIFICACIÓN EN LA TEORÍA DE LA ACCIÓN COMUNICATIVA DE JÜRGEN HABERMAS EL SER HUMANO COMO MEDIDA DE OBSERVACIÓN*
}

\author{
Rafael Alvear Moreno \\ Universidad Adolfo Ibáñez, Chile
}

\begin{abstract}
RESUMEN: La importancia de los conceptos de alienación y cosificación al interior de la teoría crítica resulta irrefutable. Ambos dan cuenta de uno de sus principales nudos de discusión desde Marx hasta el presente. Sin embargo, ¿cómo ha de ser comprendido el núcleo albergado por estos? ¿Cuál es la relación entre los diagnósticos de alienación y/o cosificación y las distintas concepciones de ser humano? ¿Cuál es además la vigencia de dicho debate para el día de hoy? A partir de un acercamiento a la teoría de Jürgen Habermas se pretende dilucidar el rol que juegan las precomprensiones antropológicas para la fundamentación de algunos de los diagnósticos actuales de alienación y/o cosificación. La tesis general del artículo es que estos últimos carecerían de valor explicativo sin una precomprensión filosófica del ser humano.

Palabras Clave: teoría crítica, alienación, cosificación, antropología, colonización, manipulación genética
\end{abstract}

RECIBIDO: junio 2019 / ACEPTADO: agosto 2019

Rafael Alvear es Doctor en Sociología de la Universidad de Flensburg, Alemania. Actualmente realiza un posdoctorado en Sociología en la Universidad Adolfo Ibáñez, enmarcado en el proyecto Fondecyt de posdoctorado de Conicyt (Folio $N^{\circ} 3190389$ ). Email: rafael.alvear@edu.uai.cl.

* El artículo presentado se basa en mi tesis de doctorado Die Stellung des Menschen in der zeitgenössischen Soziologie. Umrisse zu einer soziologischen Anthropologie. Agradezco a Hauke Brunkhorst por sus comentarios y críticas, así como a Óscar Alvear por observaciones a este texto. La traducción de las citas en alemán es de mi autoría. 


\title{
ALIENATION AND REIFICATION IN THE THEORY OF COMMUNICATIVE ACTION OF JÜRGEN HABERMAS: THE HUMAN BEING AS A METRIC OF OBSERVATION
}

\begin{abstract}
The importance of the concepts of alienation and reification within critical theory is irrefutable. Both notions express one of its main threads of discussion from Marx to the present. However, how is the core of those concepts understood? What is the relationship between the diagnosis of alienation/reification and images of the human being? What is also the validity of this debate today? Based on an approach to the theory of Jürgen Habermas, it is intended to elucidate the role played by anthropological preconceptions in the explanation and justification of the alienation and reification diagnoses. The thesis supported by this article is that both types of diagnoses would lack explanatory power without a philosophical precomprehension of the human being.

KEYwords: critical theory, alienation, reification, anthropology, colonization, genetic manipulation
\end{abstract}

ReCEIVED: June 2019/ACCEPTED: August 2019

\section{INTRODUCCIÓN}

os conceptos de alienación y cosificación juegan un rol fundamental al interior del pensamiento moderno. A pesar de que ambos ya tenían un lugar previo en la historia de la filosofía (cf. Honneth 2016), no es sino con Hegel y sobre todo con Marx - quien subraya sus componentes críticos- que alcanzan una posición de preponderancia. Por cierto, dichos conceptos pueden ser definidos en términos individuales y abstractos: mientras que la noción de alienación [Entfremdung] alude grosso modo a aquel estar o sentirse 'fuera de sí', la idea de cosificación [Verdinglichung] apunta a una forma particular de alienación en la que los seres humanos - o las relaciones entre ellos- son convertidos en cosas o percibidos como tales. No obstante sus diferentes matices, la imbricación existente entre ambos es evidente y desde Marx - aunque en diferentes momentos- es prácticamente indiscutible. Para este último, la historia de la humanidad, la historia del capitalismo, es una historia marcada por un "desarrollo creciente del ser humano" y de su “simultánea alienación” y cosificación (Fromm 1988, 49). 
Por una parte, la alienación o autoalienación [Selbstentfremdung], que se corresponde con el Marx de los Manuscritos económicos y filosóficos de 1844 y permanece aún influenciado por la estela de Hegel y Feuerbach, apunta a la pérdida que sufre el trabajador del objeto o producto por él generado (Marx 1968, 512); una circunstancia en la que este deja de asumirse "como el artífice en su apropiación del mundo" (Fromm 1988, 49). El mundo circundante le permanece tan ajeno como se observa en la descripción que hace Marx de la espontaneidad y el desacople de la división social del trabajo (cf. Marx y Engels 1978). Por otra parte, el fenómeno de la cosificación, que coincide con el Marx de El Capital (1971) y se erige como expresión privilegiada de su materialismo histórico, queda marcado por la forma concreta del fetichismo de la mercancía [Warenfetischismus]. A partir de dicha lógica se deja ver una relación alienante al interior del proceso de producción capitalista, en la cual los productos de la actividad humana adquieren una dinámica propia que somete a los trabajadores y captura sus vidas. En ello, las relaciones sociales de los trabajadores no aparecen más como "relaciones sociales de personas en sus trabajos, sino más bien como relaciones de cosas entre personas y relaciones sociales entre cosas" (Marx 1971, 87).

En este marco, el nexo interno entre ambos conceptos es, como se ha dicho, evidente. En contraposición a las interpretaciones que suponen en la transición del concepto de alienación al concepto de fetichismo de la mercanía una suerte de conversión de un Marx 'humanista' en un Marx 'antihumanista' (cf. Althusser 1968, Ulrich 2002), cabe entender ambos momentos como dos caras de una misma moneda - y de ahí su habitual uso indiferenciado. Las reflexiones que Marx desarrolla inicialmente con un cierto resabio antropológico no quedan borradas de un 'plumazo materialista', sino que se adaptan al mismo. Aquello que Marx define posteriormente "como el 'fetichismo del mundo de las mercancías' es sólo la expresión científica para el mismo fenómeno que él previamente había definido en su período hegeliano-feuerbachiano como la 'autoalienación humana", afirmaba el teórico marxista Karl Korsch (1967, 97-98).

La importancia de esta bidimensional problemática se manifiesta también en su consecutiva recepción filosófica y sociológica. Ambos conceptos han jugado un rol fundamental no solo en la obra de Marx, sino también en la posteriormente emergente teoría crítica. Tanto los 
diagnósticos de alienación como los de cosificación han sido retomados por la teoría crítica de la sociedad y releídos a la luz de nuevas perspectivas. Al interior de estas nuevas interpretaciones, el proyecto que emprende Georg Lukács en 1923 con Historia y conciencia de clase ostenta una posición de privilegio. En aquella obra se constata un intento por comprender los fenómenos de alienación y cosificación descritos por Marx a través de la teoría de la racionalización de Max Weber. El motivo de la alienación o, como Lukács (1923) aduce más corrientemente, de la cosificación, es el desarrollo capitalista, cuyo núcleo estaría caracterizado por una creciente racionalización en la que se impone el principio de la calculabilidad técnica (cf. Brunkhorst 2014, 29 ss.). Visto de este modo, la racionalización —en tanto 'destino de nuestro tiempo' (Weber) - se erige como la etiqueta común para aquellos procesos que el padre de la sociología comprensiva denominó alternadamente como "burocratización, industrialización, desarrollo hacia el capitalismo, especialización, secularización, cosificación, desencantamiento, deshumanización", etc. (Käsler 1979, 172; destacado R.A.). La creciente racionalización que Weber examinó en campos como la economía, la ciencia, el derecho, entre otros, no supone por tanto

un creciente conocimiento general de las condiciones bajo las cuales se vive. Significa en cambio algo distinto: el saber o el creer que si se quiere se puede, que no hay en principio ninguna fuerza misteriosa e imprevisible que interfiera, que antes bien todas las cosas pueden ser dominadas por el cálculo. Pero esto significa el desencantamiento del mundo. Nunca más se podrá ya echar mano a los recursos mágicos, como el salvaje para quien tales poderes existen, sino que habrá que recurrir a cálculos y recursos técnicos. (Weber 2008, 45; destacado R.A.)

Por cierto, Lukács combinó su teoría de la cosificación basada en aquel principio weberiano con una teoría de la conciencia de clase que ha sido criticada al interior y más allá del marxismo por su demostrado fracaso empírico. Como afirma Hauke Brunkhorst, la conciencia de clase que le correspondería supuestamente al proletariado - en tanto masa trabajadora - "jamás ha existido, tampoco en situaciones extraordinarias, ni después de las grandes guerras ni en las grandes crisis económicas" $(2014,36)$. No obstante lo anterior, la relevancia de su teoría 
de la cosificación para la teoría crítica de la sociedad resulta irrefutable. Tal es su trascendencia, que esta ha sido identificada, según Brunkhorst (2014), como parte del problema a resolver por parte del programa de investigación que reúne a la teoría crítica como tal. La alienación y la así delineada cosificación dan cuenta desde la formulación de Lukács del núcleo de los grandes proyectos teóricos: desde "la 'Dialéctica de la Ilustración' hasta 'El hombre unidimensional', desde la 'Crítica de la razón instrumental' hasta la 'Historia y crítica de la opinión pública' y las teorías sobre las crisis de motivación y la escasez del recurso sentido" (Brunkhorst 2014, 38); una observación que parece confirmarse —si bien también con críticas - en algunas de las propuestas más recientes al interior de esta tradición de pensamiento (cf. Honneth 2015, Rosa 2013, Jaeggi 2016 [2005]).

La teoría del que será el exponente más importante de la teoría crítica entre mediados y fines del siglo XX — esto es, de Jürgen Habermas - permanece en sintonía con lo anterior. Desde un principio es posible observar cómo Habermas se ha hecho cargo directa o indirectamente de los así concebidos diagnósticos de alienación y cosificación (cf. Habermas 1996, 170-71). Ya en su período de crítica cultural desde mediados de la década de 1950 hasta fines de los años sesentaqueda de manifiesto el denominador común de esta problemática, a saber: el progreso o racionalidad de tipo técnica (cf. Habermas 1970b). En aquel tiempo se encuentra una concepción general de la alienación que pone el acento en los efectos cosificantes de la organización del trabajo descritos por Marx (ver Habermas 1970c [1954], 1970e [1955]), aunque sin pasar por alto diferencias fundamentales con respecto a la perspectiva de este último (ver también Outhwaite 2014). En tales escritos tempranos se observa una crítica a la técnica y al pauperismo que, en concordancia con Marcuse, sitúa el problema ya no en la forma capitalista del progreso técnico o en la organización racional del trabajo, sino en el progreso técnico o en la organización racional del trabajo como tal. A partir de aquello se explica su distancia inicial con respecto a Marx:

Él [Marx] nunca abandonó la idea de que la 'maquinaria' ofrece aquella gran reserva de fuerzas productivas que sólo permanece atada mediante la 'forma de apropiación capitalista' - y que por lo mismo puede ser liberada a través de una 'Aufhebung' de dicha forma, 
de una Aufhebung de la propiedad privada. Marx nunca comprendió que esta 'maquinaria' (y todo el sistema social en su sustrato), que la técnica misma (y no primeramente una forma determinada de constitución económica) cubre (...) a los seres humanos, trabajadores y consumidores, con 'alienación'. Mucho menos pudo comprender entonces que la humanidad deba perder su partido allí donde los datos técnicos aparecen desde un principio como buenos o 'avanzados' y donde éstos por lo mismo no pueden ser percibidos en su problemática interacción con las 'fuerzas esenciales humanas' [menschlichen Wesenskräften]. (Habermas 1970e [1955], 80)

Habermas tomará una nueva posición a fines de los años sesenta - manifestada en Ciencia y técnica como 'ideología'- que, como se verá más abajo, se desmarca de la huella de Marcuse y se concentra en los efectos infecciosos o colonizadores de la racionalidad técnico-instrumental en otras esferas sociales. Sin embargo, dicha postura careció en aquel entonces de un desarrollo sistemático acabado. El inicio allí observado de lo que será luego un acercamiento prolífico a la fenomenología y a la teoría de sistemas, daba cuenta de una incompletitud que, no obstante la misma, anticipó el despliegue de una de las tesis sobre alienación y cosificación generadas por Habermas luego de su famoso 'giro lingüístico'. En lo concerniente a dichos diagnósticos, hay dos posiciones que destacan con el desarrollo del proyecto "para una teoría de la acción comunicativa" que Habermas (1970a, 7) anuncia en el prólogo a La lógica de las ciencias sociales de 1970 y marca el comienzo de aquel giro teórico: la primera es la tesis someramente adelantada acerca de la colonización de lo que Habermas entenderá, con Husserl y Schutz, como mundo de la vida mediante los denominados imperativos sistémicos. La segunda es su discusión y crítica a la manipulación genética del ser humano. Al respecto, cabe preguntarse para lo que sigue: ¿cómo son entendidas la alienación y/o cosificación al interior de ambos análisis?; ¿cómo ha de comprenderse además el núcleo de aquello que es alienado y/o cosificado? Puesto en términos más abstractos: ¿cuál es la conexión general entre los diagnósticos de alienación y/o cosificación y el ser humano? Y, finalmente: ¿cuál es su vigencia en el contexto de la sociedad contemporánea?

A partir de un análisis de la mencionada tesis de la colonización [I] y del problema de la manipulación genética [II] en la teoría de Ha- 
bermas, se pretende a continuación extraer el núcleo formal subyacente a algunos de los diagnósticos actuales de alienación y cosificación. En ello se expondrá el rol que juegan las premisas antropológicas - las imágenes de ser humano- para poder explicar ambas circunstancias. La tesis defendida por este artículo es que los diagnósticos de alienación y cosificación carecen de valor explicativo sin una precomprensión filosófica de ser humano. Mientras que en contextos de la colonización del mundo de la vida se destaca la afección de la dimensión social del ser humano, en el marco de la manipulación genética es un nivel basal y fisiológico del mismo el que se vería principalmente en entredicho. Tan cercanas están la matriz antropológica y el diagnóstico de alienación y/o cosificación que, como también puede observarse respecto de Marx, resultaría posible hablar — hacia el final- de una suerte de conexión interna entre estos; una conexión que, como se verá, parece estar más viva que nunca en la actualidad [III].

\section{LA COLONIZACIÓN DEL SISTEMA AL MUNDO DE LA VIDA}

Al concentrarse en el diagnóstico societal que la teoría habermasiana genera acerca de la alienación y la cosificación, destaca la mencionada tesis de la colonización del mundo de la vida a través de los imperativos sistémicos. La tesis de la colonización surge gracias a una observación teórica que descansa en la comprensión de la particularidad de la sociedad moderna e intenta captar sus efectos sociales patológicos. La sociedad moderna es entendida desde la Teoría de la acción comunicativa simultáneamente como sistema y mundo de la vida (Habermas 1981, 180). Mientras el sistema es comprendido como aquella dimensión material de la sociedad que engloba el accionar de tipo instrumental de esferas como la economía y la política, el mundo de la vida es comprendido como aquella raigambre social-simbólica que abarca el accionar comunicativo mediado lingüísticamente y que reúne las convicciones no cuestionadas de los sujetos ahí participantes. Si el sistema emerge a partir de un modo de coordinación altamente complejo, donde el lenguaje y la esfera de decisión de los sujetos quedan prácticamente desterrados del horizonte técnico-funcional —ahora vinculado a la lógica del dinero y el poder-, el mundo de la vida se sostiene en un tipo de coordinación donde el lenguaje condensa las interacciones y permite la 
apertura e incidencia de la voluntad de los actores involucrados (cf. Habermas 1981, Alvear 2015).

Al respecto, hay dos condiciones que deben ser satisfechas previo a la referida colonización. Primero, la diferenciación social-emergente debe profundizarse a tal punto que tenga lugar una suerte de desacoplamiento del sistema con respecto al mundo de la vida (Habermas 1981, 229 ss.). Solo en la medida en que el sistema y el mundo de la vida - otrora íntimamente vinculados - permanecen diferenciados uno del otro, pueden luego infiltrarse los imperativos de los subsistemas autónomos (dinero y poder) desde afuera hacia dentro del mundo de la vida (Habermas 1981, 522; Brunkhorst 1983, 26). Segundo, es necesaria una progresiva y selectiva "racionalización del mundo de la vida" (Brunkhorst 1983, 26), la que ha sido descrita por Habermas como una diferenciación interna de la cultura, la sociedad y la estructura de personalidad. "Con ello se cumplen", según Habermas (1981, 522), "las condiciones de una colonización del mundo de la vida: los imperativos de los subsistemas autonomizados ingresan, tan pronto cae su manto ideológico, desde afuera hacia el mundo de la vida - como señores coloniales en una sociedad tribal—y obligan [entonces] a la asimilación" interna de su forma de organización.

A través de la descripción de aquella irrupción de los medios sistémicos dinero y poder en las estructuras del mundo de la vida, Habermas renueva una vez más la teorización crítica acerca de la alienación y la cosificación. En dicha actualización, el teórico de Frankfurt procura sistematizar una posición que, como se ha mencionado, no alcanzó a ser desarrollada plenamente en Ciencia y técnica como 'ideología' y lo llevará a romper definitivamente con la impronta de sus escritos tempranos. La tesis sostenida en dicho período de que en el espacio laboral (Habermas 1970d [1958]), en el progreso técnico (Habermas, 1970c [1954]), en el sistema mismo se constata la existencia de pauperismo — de alienación y cosificación-, no puede sino ser abandonada. Ni Marcuse ni tampoco Marx han de imperar en dicho cambio de eje. Luego de Ciencia y técnica como 'ideología' y sobre todo con el desarrollo de su Teoría de la acción comunicativa, aquel espacio técnico-instrumental quedaría exento de consecuencias de tipo alienante. La organización del trabajo y las enclaustradas esferas de administración dejan de contar para Habermas como ejemplos de alienación o cosificación (cf. Celikates y Jaeggi 2009, 
161). "La complejidad, la burocracia, la economía de mercado y la juridificación ya no son un problema en sí mismo" (Brunkhorst 2006, 53). En la dimensión del sistema ya no se observaría ni alienación ni cosificación. Ambos fenómenos solo tendrían lugar en la mencionada colonización del mundo de la vida, a través de la cual dichos principios sistémicos - de racionalidad funcional-instrumental— se infiltran en la dimensión simbólica de la sociedad. En palabras de Habermas:

No es el desacoplamiento de los subsistemas controlados por los medios - y sus formas de organización — con respecto al mundo de la vida lo que conduce a una racionalización unidimensional o cosificación de la praxis comunicativa cotidiana, sino más bien la irrupción de formas económicas y de racionalidad administrativa en campos de acción que se resisten a una adaptación a los medios dinero y poder en virtud de su especialización en la tradición cultural, la integración social y la educación, y que permanecen dependientes del entendimiento como mecanismo de coordinación de la acción. (1981, 488)

Es por tanto con el sometimiento del mundo de la vida a los imperativos de los subsistemas autonomizados que aparecen aquellos "fenómenos de alienación específicos para las sociedades modernas" (Habermas 1995c, 486); una circunstancia acompañada además por efectos sociales patológicos. Así como en las colonizaciones históricogeográficas, esta ocupación no puede ser inducida sin destrozar la sociedad tribal [Stammesgesellschaft]. La vulneración del mundo de la vida no es etérea ni abstracta, sino real. Con la colonización del mundo de la vida se produciría una atrofia y agravio degenerativo de sus tres componentes (cultura, sociedad y estructura de personalidad). La irrupción del dinero y el poder en el contexto del mundo de la vida supone, así, una serie de perturbaciones vinculadas a los campos mencionados de la cultura (como pérdida de sentido), de la sociedad (como anomia) y de la estructura de personalidad (como patología psicológica). En el caso de la pérdida de sentido se trata de un trastorno de la reproducción cultural, a partir de lo cual los actores ya no pueden resolver el problema de la necesidad de entendimiento a través de su acervo cultural. "Los esquemas de interpretación aceptados como válidos fracasan y el recurso 'sentido' se vuelve escaso" (Habermas 1981, 212-13). En el caso de la anomia se observa una perturbación de la integración social, 
a partir de la cual los actores ya no pueden resolver el problema de la necesidad de coordinación por medio de los órdenes de legitimidad existentes. Las pertenencias sociales-legítimas "ya no son suficientes y el recurso "solidaridad social' se vuelve escaso" (Habermas 1981, 213). En el caso de las patologías psicológicas se constatan trastornos de los procesos de socialización, a partir de los cuales las competencias de los actores dejan de ser suficientes para "mantener la intersubjetividad de situaciones de acción definidas conjuntamente" (Habermas 1981, 213).

El escenario completo de colonización sistémica se entabla por tanto a expensas de una patologización general del mundo de la vida. Habermas ha resumido este diagnóstico de la siguiente forma:

\begin{abstract}
Estos campos de la tradición cultural, de la integración social a través de valores y normas, de la educación, de la socialización de las generaciones futuras dependen por naturaleza - dicho en términos ontológicos - del medio de la acción comunicativa para mantenerse cohesionados. Si en estos campos irrumpen ahora medios de control como el dinero y el poder (...) entonces no sólo se merman tradiciones, sino que se ven atacados los fundamentos de un mundo de la vida ya racional - la reproducción simbólica del mundo de la vida está con ello en juego. (Habermas 1996, 194-95)
\end{abstract}

Esta representación tridimensional de los fenómenos de alienación se explica entonces mediante una observación social que, sin embargo, no puede ser concebible en ausencia de estructuras antropológicamente profundas [anthropologisch tiefsitzende Strukturen] (cf. Habermas 1976, 248; 1981, 561-62). La expropiación y el agravio del mundo de la vida no flota en la nada pura, sino que es solo comprensible en relación con el ser humano que llena paradigmáticamente al mundo de la vida de vida. Cada componente del mundo de la vida que se ve dañado por la colonización sistémica, encuentra correlación con los distintos procesos de desarrollo del sujeto y con la competencia comunicativa que le está a la base - esto es, con los desarrollos cognitivos, interactivos, subjetivos y lingüísticos (cf. Habermas 1995a, 1995b). El acercamiento sistemático a la psicología evolutiva de Piaget le permite a Habermas dar cuenta de aquellas estructuras antropológicamente profundas que estarían a la base del mundo de la vida: mientras la cultura se corresponde con el desarrollo cognitivo del yo, la sociedad se correlaciona 
con el desarrollo interactivo, y la estructura de personalidad, con el desarrollo general del mismo (con el desarrollo de su subjetividad). Estas tres instancias se despliegan en el medio del lenguaje - gracias al desarrollo lingüístico - que hace posible que cada componente permanezca en contacto con los demás.

A partir de lo anterior, la alteración del mundo de la vida se vuelve concreta y visible. Cada efecto cosificante en el mundo de la vida restringiría finalmente el sustrato de las competencias que el yo adquiere en su desarrollo y lo convierten en un sujeto capaz de conocimiento, lenguaje y acción. Al respecto, lo que está en juego no es la mera inhibición del uso de aquellas competencias — como se puede constatar en la esfera sistémica-, sino que de su invasivo perjuicio, tan pronto como los medios dinero y poder - llegado el caso también el derecho- echan raíces en campos de acción que hasta entonces permanecían vinculados al mundo de la vida y al lenguaje como mecanismo de coordinación de la acción. Allí donde tiene lugar la colonización del mundo de la vida es el sujeto - capaz de conocimiento, lenguaje y acción - el que queda en entredicho y sufre de aquella experiencia alienante.

Esta situación puede, por cierto, ser rastreada en la vida cotidiana. En la actualidad, no resulta difícil reconocer dicha dinámica — para mencionar un ejemplo- en las universidades y escuelas, donde la comunicación científica y pedagógica se muestran transgredidas y cada vez más asimiladas a la lógica del dinero. Al respecto, basta con echar un vistazo a los planes de estudio y/o test estándares "para constatar que la colonización monetaria" no solo obliga a aquellas instituciones educativas a adecuarse a procesos propios del mercado (Brunkhorst y Müller-Doohm 2009, 11; destacado en original), sino que posibilita una riesgosa transformación de los sujetos ahí involucrados. En este sentido, queda abierta la interrogante respecto de las posibilidades de medios como el dinero y el poder de transgredir e incluso desmontar los procesos de aprendizaje de los individuos (esto es: los procesos de desarrollo cognitivo, interactivo, subjetivo y lingüístico) a través de los cuales estos se convierten propiamente en sujetos. La trascendencia de dicha pregunta es evidente. Lo que estaría en juego no sería por tanto el mero ejercicio del lenguaje y de la competencia comunicativa - como se observa en el sistema-, sino la base sobre la cual ambos se erigen 
como tales. Por cierto, en aquel lugar aparecería un nuevo proceso de desarrollo del sujeto que preparase al niño o recién nacido para la sociedad. ¿Para qué sociedad? y ¿qué tipo de sujeto sería formado allí? son las interrogantes que pueden levantarse a propósito de la situación actual.

\section{LA MANIPULACIÓN GENÉTICA}

Partiendo con Habermas y Arnold Gehlen de la conexión interna de la técnica con la estructura de acción y/o pensamiento instrumental (cf. Gehlen 1957; Habermas 1977, 196; Habermas 1969, 56, 82), no resulta difícil comprender por qué la colonización sistémica y su lógica funcional han llegado a inmiscuirse en dimensiones hasta hace poco impensadas. La expresión viva de esta colonización del cálculo medio-fin puede encontrarse -en el contexto del desarrollo de la técnica preimplantacional y de la investigación de células madre- en el libro El futuro de la naturaleza humana: ¿hacia una eugenesia liberal? de 2001, donde Habermas analiza el problema de la manipulación de la dotación genética del ser humano. A pesar de que la discusión sobre la ingeniería genética y su aplicación liberal ya había obtenido una respuesta clara (afirmativa) en lugares como Estados Unidos, esta carecía de resonancia en regiones como Europa. En esta última, la pregunta no guardaba relación con la forma que debía adoptar tal shopping in the genetic supermarket, como afirma Habermas $(2006,128)$ respecto del caso norteamericano, sino más bien con la previa toma de posición acerca de si esta debiese tener lugar o no como tal.

El detonante de aquel debate proviene tanto de la evidencia y las posibilidades de la avanzada ingeniería genética como de la conferencia y posterior libro de Peter Sloterdijk, Normas para el parque humano, de 1999. Mediante una crítica al humanismo de estilo heideggeriano y una recepción de la idea del superhombre de Nietzsche, Sloterdijk aboga con el ahí formulado concepto de antropotécnica por la posibilidad de una "reforma genética de las propiedades de la especie" (Sloterdijk 1999, 50) que, como lo propusiese Platón en su reflexión política, queda resumida en la idea de un parque humano. En este zoológico de nuevo cuño se estaría frente a un "cultivo sistemático de ejemplares humanos más cercanos al arquetipo original" (Sloterdijk 1999, 50). El objetivo 
estaría puesto en alcanzar una mejor forma de homoestasis, en la medida en que, según Sloterdijk, "ambos óptimos de la especie humana, la valentía guerrera por un lado y la prudencia filosófica por otro, están encarnados en el tejido público con igual fuerza" $(1999,53)$.

Sin perjuicio de si lo anterior se revela como mera elucubración, como quimera o, incluso, como una posibilidad real, la pretensión de Habermas (2006 [2001]) reside en auscultar críticamente los peligros y las consecuencias que supondría dicha manipulación genética. Mientras que el teórico de Frankfurt persigue dar cuenta en un primer término de las intervenciones a la dotación genética humana que, en oposición a la terapéutica, define como propias de una eugenesia liberal (cf. Habermas 2006, 38), en un segundo término pretende destacar las repercusiones morales que implica la misma para la especie en general. Si la primera, como se busca argumentar, alude a la cosificación del género humano [a], la segunda apunta a los vestigios alienantes que terminan cercenando la autocomprensión del sujeto en tanto que actor-responsable (Habermas 2006,28$)[b]$.

[a] El análisis de Habermas acerca de la posibilidad de injerir libremente en la constitución genética del ser humano se basa en una recepción de la distinción fenomenológica de Helmuth Plessner (1975) entre 'ser-cuerpo' [Leibsein] y 'tener-cuerpo' [Körperhaben]; una distinción que da cuenta del carácter o aspecto doble del ser humano, en tanto que ser humano fisiológico (en bruto) y sociocultural (sujeto) (cf. Alvear, por publicarse). Según Plessner, el ser humano 'es' en virtud de su condición animal 'su-cuerpo', mientras que simultáneamente puede comportarse respecto del mismo con distancia, como si este fuera un 'objeto' que puede ser aprehendido de manera externa o, dicho con Plessner, excéntrica (Habermas 1985, 369; Plessner 1975, 294). De ahí que el ser humano tenga cualidades corporales internas (fisiológicas) y externas (socioculturales), las que a su vez permanecen íntimamente vinculadas. "[S]ólo en la medida en que 'es' su cuerpo [Leib] a lo largo de su vida", puede un sujeto estar en condiciones de tener o poseer "su cuerpo [Körper]" (Habermas 2006, 89). El modo de experiencia del 'ser-cuerpo' se erige así como basis animal sobre la cual se despliega el desarrollo del sujeto - hacia la mencionada competencia comunicativa.

Visto de este modo, con el nacimiento comenzaría un proceso de deslindamiento en el que la primacía de la dimensión fisiológica empie- 
za a ser dejada atrás — sin por ello ser abandonada del todo. Al respecto, la diferenciación entre el destino natural del ser humano fisiológico y el destino social del sujeto adquiere relevancia. A partir del desprendimiento de la simbiosis con la madre, el niño se integraría, según Habermas, en un mundo de sujetos que le salen al paso, "que le dirigen la palabra y que pueden hablar con él (...). No es sino en la esfera pública de una comunidad lingüística que el ser natural puede transformarse en individuo y en persona racional" (Habermas 2006, 65). Es en esta red simbólica

de relaciones recíprocas de reconocimiento entre personas que actúan comunicativamente, [que] el recién nacido es identificado como 'uno más', aprendiendo además 'paulatinamente a identificarse a sí mismo' como sujeto, como parte o miembro de su comunidad social y como 'individuo único, inconfundible y, al mismo tiempo, moralmente irremplazable'. (Habermas 2006, 66)

Sin embargo, esta distinción entre la naturaleza que 'somos' y la condición social que 'desarrollamos' parece volverse difusa con la manipulación genética del que está por nacer (Habermas 2006). Un factor cosificante se posiciona entre ambos polos. Con la determinación de intervenir genéticamente en la disposición natural del ser humano, asoma esta nueva forma de tecnificación de la naturaleza humana como resultado del cálculo medio-fin. En este marco y de manera diferente "a la intervención clínica, el material genético es manipulado desde la perspectiva de un actor instrumental que, en el campo en cuestión, introduce de manera 'colaborativa' un estado deseado a partir de sus propios objetivos" y concepciones (Habermas 2006, 92-93). Visto de esta manera, todo tiende hacia una cosificación del ser humano que, primero, se presenta como autoinstrumentalización y autooptimización; segundo, queda definida por las preferencias y orientaciones de valor de terceras personas; $y$, tercero, repercute en el estatus del ser humano en tanto especie (véase al respecto el caso reciente de manipulación del ADN de gemelas en China con el objetivo de hacerlas resistentes al VIH [Bahnsen 2018]). En la medida en que se aplica en la actualidad esta eugenesia liberal y se "trabaja en clones reproductivos de organismos humanos se impone", según Habermas, "la perspectiva de que la especie humana podría tomar rápidamente el control de su evolución 
biológica en su mano" (Habermas 2006, 42). Tan pronto como el ser humano lleva a cabo esta suerte de autotransformación de la especie, parece adoptar un nuevo rol en el devenir de la historia natural, a saber: como coparticipante de la evolución o, dicho en términos teológicos, como colaborador de dios [Mitwirkende Gottes].

En razón de lo precedente, el ser humano pondría a disposición la basis fisiológica que define su género por naturaleza (Habermas 2006, 53 ), con lo cual desaparece la "distinción categorial antropológicamente fundada" (Habermas 2006, 121) entre basis natural no-modificable - aquello que Kant denominó reino de la necesidad - y espacio social-cultural abierto a la acción —reino de la libertad. La ingeniería genética desplaza la frontera original entre ambos reinos, implicando una disolución de la famosa distinción de la antropología kantiana entre antropología fisiológica y pragmática. Según Kant, mientras la antropología fisiológica apunta a la investigación de lo que "la naturaleza hace del ser humano" (Kant 1983, 29), la antropología pragmática se ocupa de examinar aquello que el ser humano, "en tanto que agente libre hace, o puede y debe hacer, de sí mismo" (Kant 1983, 29). ¿Qué contextura debe adquirir la antropología fisiológica si el ser humano desplaza en su rol a la naturaleza? ¿Ha de comprenderse como aquella dirección antropológica que se hace cargo de lo que el ser humano hace de sí mismo? La similitud con la dimensión pragmática disolvería aquella diferenciación.

Tan pronto como tenga lugar la manipulación instrumental del genoma humano desaparece entonces la distinción categorial entre lo objetivo y lo subjetivo, lo natural y lo artificial, lo fisiológico y lo pragmático. La distinción procedente de los escritos antropológicos kantianos entre ser humano en bruto [Rohmensch] y sujeto [Subjekt] deja entonces de tener un rol de importancia (sobre el concepto de ser humano en bruto ver Kant 1983, 281-82; Ak. XV, 780-82; también Alvear, por publicarse). La diferencia plessneriana entre 'ser-cuerpo' y 'tener-cuerpo' no solo se vuelve problemática, sino que degenerativa. El 'ser-cuerpo' del ser humano fisiológico o en bruto sería modificado voluntariamente por terceros, implicando así su sometimiento irremediable frente al 'tenercuerpo' del sujeto extraño capaz de acción y decisión. Y esto último no puede ser vivenciado con ausencia de consecuencias relevantes para el futuro sujeto manipulado. 
[b] Esta mencionada superposición del reino de la libertad en el reino de la necesidad, de lo artificial en lo natural, del 'tener-cuerpo' en el 'ser-cuerpo', del sujeto en el ser humano fisiológico o en bruto, adquiere un carácter corrosivo en la medida en que "al adolescente eugenésicamente manipulado se le revela su cuerpo como algo producido" por "la perspectiva reificante de productores o entusiastas" terceros (Habermas 2006, 90). Al respecto, la cosificación genética no desaparece con el futuro desarrollo del yo y la consecutiva formación del sujeto, sino que sigue atormentando a este último con una suerte de estela alienante. La desdiferenciación de la distinción entre lo recibido por naturaleza y lo artificialmente realizado, que "resulta constitutivo para nuestra autocomprensión en tanto que miembros de la especie" (Habermas 2006, 83), perturba ciertamente al mundo de la vida y sus cimientos; esto último de dos formas.

En primer término, aquella desdiferenciación entre naturaleza nomodificable y decisión libre altera la estructura completa de la experiencia moral. El problema de la intervención genética pone en cuestión la autocomprensión normativa del involucrado. Hasta entonces uno podía presumir que

los dispositivos genéticos del recién nacido y, con ello, las condiciones orgánicas de partida para la historia de vida futura permanecían ajenos a la programación y manipulación intencional de otras personas (...) Nuestra historia vital está hecha de un material que podemos 'adoptar' y, en el sentido de Kierkegaard, 'asumir responsablemente' como propio. (Habermas 2006, 29)

Aquel carácter de inalterabilidad de lo (naturalmente) recibido al nacer es una condición a partir de la cual nos podemos concebir como únicos autores de nuestra vida. Esta es además una presuposición necesaria para el poder-ser-sí-mismo [Selbstseinkönnen] que Habermas identifica con Kierkegaard como respuesta a la interrogante ética acerca del éxito o el fracaso de la vida personal. Sin embargo, es evidente que con el conocimiento de la programación del genoma propio, esta obviedad sobre la singularidad de la vida individual pueda ser destruida - con consecuencias paralelas para la esfera social del sujeto.

En segundo término - y relacionado con lo anterior-, la desaparición de la frontera entre lo natural y lo artificial tiene como resultado 
la confección de un nuevo tipo de relaciones asimétricas entre sujetos y/o personas, en la medida en que se pone en entredicho la base para la igualdad de derechos entre miembros de una misma comunidad moral (Habermas 2006, 77). Tan pronto como un sujeto toma una decisión respecto de las disposiciones orgánicas de un otro,

la simetría de responsabilidad entre personas libres e iguales queda restringida (...). El adolescente en crecimiento podrá algún día hacerse cargo de su historia vital y de aquello que ha llegado a ser. Él podrá comportarse de manera reflexiva respecto de su proceso de formación, podrá generar una autocomprensión revisora y reconciliarse retrospectivamente con la responsabilidad asimétrica que los padres tienen respecto de sus hijos. Esta posibilidad de una apropiación autocrítica de la propia historia formativa no le está dada en igual forma al manipulado genéticamente. La persona adulta permanecería ciegamente dependiente de la decisión incontrolable [no-revisable] de una otra persona, sin tener la posibilidad de conformar —en el camino de una autorreflexión ética - una simetría de responsabilidad necesaria para el trato entre iguales. (Habermas 2006, 31)

Es justamente esta imposibilidad de apropiarse críticamente de la formación histórica personal lo que posibilita la generación de relaciones asimétricas. Y es esto mismo lo que posteriormente será vivenciado por los sujetos manipulados como alienación, en tanto aquello que previamente aparecía como obviedad queda desarticulado desde su base. El sujeto, que debiese sentirse en su propio cuerpo como en casa, se confronta así con la extrañeza de la decisión de un tercero, que ahora permanece encarnada en el propio cuerpo. Distinto a como se observa al interior del marxismo tradicional, que concibe el trabajo como una praxis cosificante que ha de ser liberada mediante la Aufhebung de su forma actual, el acto cosificante de la manipulación genética se muestra como un callejón sin salida. El proceso de cosificación ahí observable no solo es estremecedor, sino que además es irreversible. Allí donde la cosificación tiene lugar en la disposición fisiológica del ser humano, no hay marcha atrás. La posibilidad de desenmascarar o confrontar incluso aquella decisión de un tercero no resuelve la cuestión. La verdad puede también ser vivenciada como problema o prisión. Esto explica además por qué la alienación — más allá de las razones reales - pueda ser ex- 
perimentada incluso como confortable (Marx y Engels 1972, 37). Si, no obstante esto último, resultase mejor llevar una vida verdadera con o una vida falsa $\sin$ conciencia de aquellos fenómenos alienantes, es una interrogante tan difícil de responder como paradójica en sí misma. La dificultad de esta dicotomía se explica probablemente por el hecho de que la respuesta a tal pregunta dependa directa o indirectamente de la forma en que es comprendida la vida humana.

\section{DISCUSIÓN FINAL: SOBRE LA IMBRICACIÓN INTERNA ENTRE ALIENACIÓN/COSIFICACIÓN Y SER HUMANO EN EL PRESENTE}

A través del análisis de la tesis de la colonización del mundo de la vida y de la discusión sobre la manipulación genética en la teoría de Habermas, ha podido observarse cómo el progreso técnico ha modificado diferentes áreas humanas, implicando con ello consecuencias importantes en materia de alienación y de cosificación. Ambos conceptos pueden ser usados ciertamente de manera indiferenciada - como en el contexto de la tesis de la colonización - o diferenciada - como lo he sostenido en la discusión sobre la manipulación genética. Sin embargo, ambos han de considerarse en cualquier caso como dos caras de una misma meda1la. ${ }^{1}$ Allí donde hay cosificación hay alienación y normalmente también a la inversa. Sin embargo: ¿qué es aquello que se esconde detrás de este escenario completo?

Al observar las diversas dinámicas de alienación y cosificación se vuelve más claro aquello que está en juego. Como se ha observado, la colonización del mundo de la vida y la manipulación genética no implican consecuencias de índole meramente abstracta, sino que concretas y reconocibles a partir de la figura del ser humano. En el contexto de la tesis de la colonización se ha mostrado cómo la lógica sistémica transgrede el mundo de la vida. En ello se constata un perjuicio invasivo

\footnotetext{
${ }^{1}$ Habermas mismo no traza ninguna diferencia sistemática entre ambos conceptos —al menos en lo que respecta a ambas discusiones. Si en el contexto de la tesis de la colonización no vale la pena distinguir entre alienación y cosificación, se ha pretendido diferenciarlos ligeramente respecto de la discusión sobre la manipulación genética para justamente distinguir entre un acto cosificante concreto y las consecuencias alienantes que este comporta.
} 
de aquel espacio simbólico. Cada efecto cosificante en el mundo de la vida, que se manifiesta en trastornos de la cultura (pérdida de sentido), de la sociedad (anomia) y de la estructura de personalidad (patologías psicológicas) cercena no solo el uso, sino además el sustrato de las competencias que el sujeto ha adquirido en su desarrollo, a saber: competencias cognitivas, interactivas, subjetivas y lingüísticas. A partir de lo mismo se genera un profundo menoscabo de la competencia comunicativa del sujeto en su totalidad. En el contexto de la discusión sobre la manipulación genética se observa un agravio que aqueja —más allá de la condición del mismo como ser social — ante todo el estatus genérico del ser humano (su dimensión fisiológica). La disposición natural del ser humano - su condición corporal- es modificada a través de las preferencias y orientaciones de valor de terceros, con lo cual la distinción categorial entre lo natural y lo artificial, el 'ser-cuerpo' y el 'tener-cuerpo' parece desaparecer instantáneamente. Por cierto que este fenómeno cosificante supone luego efectos alienantes para la futura comprensión del sujeto manipulado. Sin embargo, esto último obedece a un acto de resonancia alienante detonado por la cosificación de la basis genérica del ser humano, esto es: de su especificidad corporal.

Con todo ello se vuelve evidente dónde descansa el peso de dichos fenómenos. Tanto en el contexto de la colonización del mundo de la vida como en el marco de la discusión sobre la manipulación genética, es el ser humano el que hace de contrapeso a los diagnósticos de alienación y cosificación. Si se observan estos últimos de forma abstracta puede constatarse rápidamente cómo ambos configuran el reverso negativo de una cara marcada por el ser humano (cf. Bloch 1969, 123). Para ponerlo en una frase: sin antropología, sin ser humano no puede haber diagnóstico de alienación o cosificación. De otro modo: ¿qué es aquello que se aliena o cosifica? Para decirlo con relación a la teoría de Habermas: solo una premisa antropológica que comprende al ser humano social (sujeto) junto a la idea de una competencia comunicativa - que reúne facultades como la cognitiva, interactiva, subjetiva y lingüística - puede dar cuenta de la forma alienante desencadenada por la colonización del mundo de la vida. Con respecto a la manipulación genética puede observarse asimismo que es solo una concepción fisiológica fuerte del ser humano no-manipulado (del ser humano en bruto) lo que permite comprender la magnitud de la cosificación de quien ha 
sido genéticamente manipulado. Si entonces la lógica sistémica y su colonización del mundo de la vida resulta alienante para la dimensión social del ser humano (sujeto), el acto cosificante de la manipulación genética se concentra - aunque no exclusivamente - en la dimensión fisiológica del mismo (en el ser-cuerpo de aquel ser humano en bruto). Sin una precomprensión general acerca del ser humano no sería posible diagnosticar si acaso este sufre de alienación y/o cosificación.

El problema de la racionalidad técnico-instrumental no es por tanto una cuestión abstracta, sino que real y medible conforme al ser humano. El ser humano remite, como se ha dicho, al lado positivo de una distinción que tiene a la deshumanización (en tanto alienación o cosificación) como su lado negativo. El diagnóstico de alienación o cosificación ha sido siempre - desde Marx a Lukács, desde Horkheimer y Adorno hasta Habermas - un diagnóstico negativo que pone al ser humano en el centro de atención, pero no para ocultar su entorno, sino para observarlo y comprenderlo mejor con relación al mismo. La lógica instrumental encarnada en el progreso técnico funge así como catalizador de procesos de alienación y cosificación en los cuales el ser humano se pone a sí mismo en entredicho. En los Manuscritos económicos y filosóficos de 1844, la vieja sentencia de Marx acerca de estos fenómenos demuestra un razonamiento propiamente reflexivo. Según Marx, el trabajador "produce el capital, el capital lo produce a él, él se produce entonces a sí mismo, y el ser humano como trabajador, como mercancía, es el producto del movimiento completo" (Marx 1968, 523). Aquella sentencia se apoya en la crítica a la religión, que no por nada se ofrece como premisa o "presuposición de toda crítica" (Marx 1961, 378). Así como para Feuerbach, para Marx es el ser humano el que crea a dios - para luego poder ser creado por él. Si se intentase identificar dicha estructura en la teoría habermasiana — con un ojo puesto en la contemporaneidad - queda claro cómo aquel movimiento dialéctico ha encarnado nuevas formas. Para parafrasear la mencionada sentencia: el ser humano social (sujeto) produce el dinero, el poder y la posibilidad de la manipulación genética, el dinero, el poder y la manipulación genética lo producen a él (como sujeto y como ser humano en bruto), él se produce entonces a sí mismo, y el ser humano como sujeto y como ser humano en bruto es el producto del movimiento completo. 
La velocidad de esta dinámica técnico-instrumental es complementada, así, como se observa en el diagnóstico de Marx, por circunstancias de emergencia. En esta tiene lugar una espiral que, si bien postula a los seres humanos como artífices y realizadores, despoja a estos últimos de su voluntad y conciencia (Kosik 1973, 191), dando rienda suelta a la autodefinición de la situación (Han 2011, 15). Esta dinámica completa evade el poder de decisión del ser humano para finalmente - como afirma Hans Freyer paradójicamente cerca de la teoría crítica tempranaorientarse de acuerdo a la técnica:

El ser humano ya no le pregunta al medio si es oportuno, sino que el medio le pregunta al ser humano si es que éste debiese activarlo por el solo hecho de poder hacerlo. Botones que pueden ser presionados atraen, seducen. Éstos prefiguran casi la decisión; mientras más grande es el efecto que puede ser generado por los mismos, tanto más. (Freyer 1956, 167)

En el marco de este carácter seductor o coercitivo de la técnica de una sociedad autoalienante (Horkheimer y Adorno 2013, 129), la pregunta kantiana ¿qué debo hacer? parece carecer de sentido. "La pregunta de si un día el ser humano querrá solamente porque puede" (Freyer $1956,167)$ parece no solo planteada, sino que incluso respondida ya afirmativamente por los hechos. ${ }^{3}$ El poder de poder expropia a quien debe decidir de su libre capacidad de dictaminación y lo degrada a meras tareas de posibilitación. En el universo actual de la técnica instrumental, el ser humano se transforma en una suerte de prestador de competencias que simplemente hace posible su despliegue. Marx ya lo advertía: "Al ser humano, que no es más que un trabajador (...) le están dadas sus propiedades humanas sólo en cuanto permanecen disponibles para el capital que le es ajeno" (Marx 1968, 523). Confrontado con esta reducción y restricción del ser humano, que tiene lugar en la realidad factual (Kosik 1973, 88), el pensamiento crítico procura captar la cosa en su raíz

\footnotetext{
${ }^{2}$ Agradezco una larga conversación con Juan Miguel Chávez al respecto.

${ }^{3} \mathrm{La}$ interrogante por las implicancias prácticas que suponen escenarios descritos como la colonización monetaria de la educación y la manipulación genética asomaría así intrascendente, en virtud de que los estudiantes ya habrían adoptado la lógica de la competencia y de que, con respecto al caso de intervención genética en China, las gemelas manipuladas por He Jiankui "nacieron sanas y felices" (cf. EFE 2018).
} 
(Marx 1961, 385). Y la raíz de todas las cosas sociales es, como lo ha parafraseado Ernst Bloch $(1969,145)$, el ser humano. Con esto último queda resumido el centro del problema: en la crítica de la alienación y la cosificación no es otra cosa que el ser humano aquello que debe ser devuelto a su lugar. Por ello, no es ninguna coincidencia el que la crítica de Marx a la religión termine con la conclusión de que el ser humano sea para sí mismo "el ser más elevado, [el que termine entonces; R.A.] con el imperativo categórico de derribar todas las relaciones en las cuales el ser humano aparece como un ser degradado, esclavizado, abandonado, despreciado" (Marx 1961, 385; destacado en original).

El desafío está puesto en superar las circunstancias de alienación y/o cosificación para posibilitar la vuelta del ser humano a sí mismo. La imbricación interna se vuelve entonces evidente: allí donde tienen lugar el diagnóstico y la crítica a la alienación y la cosificación, se escucha un reparo para que el ser humano no vaya a pérdida. A pesar de su anclaje en la tradición crítico-moderna, este reparo, como se ha visto, goza de absoluta vigencia. La espontaneidad y externalidad de lo social - crecientemente ajeno de quienes lo hacen posible-, genera por su misma condición de objetividad emergente una proliferación de situaciones de alienación y cosificación que, si bien han sido ilustradas a partir de los casos de colonización monetaria e intervención genética, sobrepasan largamente la especificidad de estas últimas. Las dinámicas enajenantes encarnan con el avance de la sociedad cada vez nuevas formas, las que recuerdan el andar propio de la dialéctica del progreso: mientras mayor es el desarrollo, más refinadas son también las formas de reificación. La tendencia a la multiplicación de tales circunstancias detonadas por la inmersión contingente de la racionalidad instrumental resulta así prácticamente una obviedad. El desarrollo de tecnologías para la cotidianeidad, la misma inteligencia artificial, la aceleración de las formas de vida, así como también la explotación del medio ambiente, etc., todas estas son circunstancias que están marcadas por el surgimiento paralelo de procesos de alienación y/o cosificación que terminan por redundar — para bien y para mal — en quien ha posibilitado su avance: el ser humano.

El reparo ya no puede quedarse entonces, como en Marx y el Habermas temprano, solamente en el carácter corrosivo de la esfera del trabajo, sino que adquiere nuevos contornos, capturando nuevas regiones y obligando además con ello a trascender la mera discusión 
teórico-filosófica — aquella que se ha intentado desplegar aquí. La vigencia concreta de dichas dinámicas de alienación y cosificación exige el desarrollo de un espacio consecuente para la generación de comunicación político-deliberativa en la búsqueda por diseñar después de todo directrices de gobierno, esto es, políticas públicas que puedan hacerse cargo de la relevancia que comporta dicha problemática. Los grandes relatos que, desde Marx, versan de utopías revolucionarias han caído (véase sobre el componente teórico-crítico de esta cuestión Heller y Alvear 2018). Si esto es así, de lo que se trata entonces es de confrontar las distopías alienantes/cosificantes de manera colectiva (Heller y Alvear 2018). Esto supone abrir el debate para una cuestión que, a pesar de sus componentes altamente técnicos, no puede evadir el filtro de legitimidad propio de la opinión pública. Si, luego, la posibilidad de una mejor convivencia o superación relativa incluso de tales dinámicas de alienación y cosificación, ha de residir o no en una suerte de control social público que ponga al descubierto la pseudoconcreción de la que hablaba Karel Kosik e intente una vez más trascender su apariencia para alcanzar lo concreto, para descolonizar los espacios social-simbólicos conquistados por la lógica técnico-instrumental, todo aquello es una interrogante teórica de respuesta eminentemente práctica.

\section{REFERENCIAS}

Althusser, L. 1968. La revolución teórica de Marx. México D.F.: Siglo XXI.

Alvear, R. 2015. El lenguaje como herramienta para la configuración de una teoría crítica de la sociedad. Un acercamiento a la teoría de Jürgen Habermas. Persona y Sociedad 29, 85-111.

Alvear, R. Por publicarse. Antropología filosófica: entre naturaleza y cultura.

Bahnsen, U. 2018. Darf er, was er kann? Die Zeit. Disponible en: https://www.zeit. de/2018/49/crispr-china-genmanipulation-he-jiankui-zwillingsbabys-ethik

Bloch, E. 1969. Karl Marx und die Menschlichkeit. Utopische Phantasie und Weltveränderung. München: Rowohlt.

Brunkhorst, H. 1983. Kommunikative Vernunft und rächende Gewalt. Sozialwissenschaftiche Literaturrundschau 8/9, 7-34.

Brunkhorst, H. 2006. Habermas. Leipzig: Reclam.

Brunkhorst, H. 2014. Kritik und kritische Theorie. Baden-Baden: Nomos.

Brunkhorst, H. y Müller-Doohm, S. 2009. Intellektuelle Biographie. En Habermas Handbuch, editado por H. Brunkhorst, R. Kreide y C. Lafont. Stuttgart: J.B. Metzler, 1-14. 
Celikates, R. y Jaeggi, R. 2009. Technik und Verdinglichung. En Habermas Handbuch, editado por H. Brunkhorst, R. Kreide y C. Lafont. Stuttgart: J.B. Metzler, 155-64.

EFE 2018. Científico chino justifica la manipulación genética y dice que hay otro embarazo. Disponible en: https://www.efe.com/efe/america/sociedad/ cientifico-chino-justifica-la-manipulacion-genetica-y-dice-que-hay-otroembarazo/20000013-3826493

Freyer, H. 1956. Theorie des gegenwärtigen Zeitalters. Stuttgart: Verlags-Anstalt.

Fromm, E. 1988. Das Menschenbild bei Marx. Frankfurt am Main: Ullstein Sachbuch.

Gehlen, A. 1957. Die Seele im technischen Zeitalter. Hamburg: Rowohlt.

Habermas, J. 1969. Technik und Wissenschaft als ,Ideologie‘. Frankfurt am Main: Suhrkamp.

Habermas, J. 1970a. Zur Logik der Sozialwissenschaften. Frankfurt am Main: Suhrkamp.

Habermas, J. 1970b. Arbeit, Erkenntnis, Fortschritt. Aufsätze 1954-1970. Amsterdam: Verlag de Munter.

Habermas, J. 1970c. Die Dialektik der Rationalisierung. En Arbeit, Erkenntnis, Fortschritt. Aufsätze 1954-1970. Amsterdam: Verlag de Munter, 7-30.

Habermas, J. 1970d. Soziologische Notizen zum Verhältnis von Arbeit und Freizeit. En Arbeit, Erkenntnis, Fortschritt. Aufsätze 1954-1970. Amsterdam: Verlag de Munter, 56-74.

Habermas, J. 1970e. Marx in Perspektiven. En Arbeit, Erkenntnis, Fortschritt. Aufsätze 1954-1970. Amsterdam: Verlag de Munter, 75-80.

Habermas, J. 1976. Zur Rekonstruktion des Historischen Materialismus. Frankfurt am Main: Suhrkamp.

Habermas, J. 1977. Kultur und Kritik. Frankfurt am Main: Suhrkamp.

Habermas, J. 1981. Theorie des kommunikativen Handelns, Vol. 2. Frankfurt am Main: Suhrkamp.

Habermas, J. 1985. Der philosophische Diskurs der Moderne. Zwölf Vorlesungen. Frankfurt am Main: Suhrkamp.

Habermas, J. 1995a. Vorlesungen zu einer sprachtheoretischen Grundlegung der Soziologie. En Vorstudien und Ergänzungen zur Theorie des kommunikativen Handelns. Frankfurt am Main: Suhrkamp, 11-26.

Habermas, J. 1995b. Notizen zur Entwicklung der Interaktionskompetenz. En Vorstudien und Ergänzungen zur Theorie des kommunikativen Handelns. Frankfurt am Main: Suhrkamp, 187-225.

Habermas, J. 1995c. Replik auf Einwände. En Vorstudien und Ergänzungen zur Theorie des kommunikativen Handelns. Frankfurt am Main: Suhrkamp, 475570 .

Habermas, J. 1996. Die Neue Unübersichtlichkeit. Kleine politische Schriften. Frankfurt am Main: Suhrkamp. 
Habermas, J. 2006. Die Zukunft der menschlichen Natur. Auf dem Weg zu einer liberalen Eugenik? Frankfurt am Main: Suhrkamp.

Han, B. 2011. Shanzhai. Dekonstruktion auf Chinesisch. Berlin: Merve.

Heller, Á. y Alvear, R. 2018. 'En casi todo el mundo el capitalismo existe sin democracia': Capitales flotantes, tiranías democráticamente electas y redistribución invertida en la perspectiva de Ágnes Heller. Cuadernos de Teoría Social 4 (8), 97-114.

Honneth, A. 2015. Verdinglichung. Eine anerkennungstheoretische Studie. Frankfurt am Main: Suhrkamp.

Honneth, A. 2016. Vorwort. En Entfremdung Zur Aktualität eines sozialphilosophischen Problems, editado por R. Jaeggi. Frankfurt am Main: Suhrkamp, 7-10.

Horkheimer, M. y Adorno, T. 2013. Dialektik der Aufklärung. Frankfurt am Main: Fischer Taschenbuch.

Jaeggi, R. 2016 [2005]. Entfremdung Zur Aktualität eines sozialphilosophischen Problems. Frankfurt am Main: Suhrkamp.

Kant, I. 1983. Anthropologie in pragmatischer Hinsicht. Stuttgart: Reclam.

Kant, I. XV. Kants gesammelte Schriften [Ak.], ed. Koeniglichen Preussischen Akademie der Wissenschaften. Berlin: Walter de Gruyter, 29 vols.

Käsler, D. 1979. Einführung in das Studium Max Webers. München: Beck'sche Elementarbücher.

Korsch, K. 1967. Karl Marx. Frankfurt am Main: Europäische Verlagsanstalt.

Kosik, K. 1973. Dialektik des Konkreten. Frankfurt am Main: Suhrkamp.

Lukács, G. 1923. Geschichte und Klassenbewußtsein. Studien über marxistische Dialektik. GLW.

Marcuse, H. 1993. El hombre unidimensional. México D.F.: Planeta de Agostini.

Marx, K. 1961. Zur Kritik der Hegelschen Rechtsphilosophie. Einleitung. En Marx und Engels Werke. Berlin: Dietz, Vol. 1, 378-91.

Marx, K. 1968. Ökonomisch-philosophische Manuskripte aus dem Jahre 1844. En Marx und Engels Werke. Berlin: Dietz, Vol. 40, 465-590.

Marx, K. 1971. Das Kapital. En Marx und Engels Werke. Berlin: Dietz, Vol. 23.

Marx, K. y Engels, F. 1972. Die heilige Familie oder Kritik der kritischen Kritik gegen Bruno Bauer und Kunsorten. En Marx und Engels Werke. Berlin: Dietz, Vol. 2, 3-223.

Marx, K. y Engels, F. 1978. Die deutsche Ideologie. En Marx und Engels Werke. Berlin: Dietz, Vol. 3, 13-530.

Outhwaite, W. 2014. Kontinuitäten und Diskontinuitäten in Habermas' Auseinandersetzung mit dem Historischen Materialismus. En Habermas und der Historische Materialismus, editado por S. Rapic. Freiburg/München: Karl Alber, 37-46.

Plessner, H. 1975. Die Stufen des Organischen und der Mensch. Berlin und New York: Walter de Gruyter. 
Rosa, H. 2013. Beschleunigung und Entfremdung. Frankfurt am Main: Suhrkamp. Sloterdijk, P. 1999. Regeln für den Menschenpark. Frankfurt am Main: Suhrkamp. Ulrich, G. 2002. Der Grund der Gesellschaft: Subjekt und Struktur bei Karl Marx. En Der soziologische Blick. Vergangene Positionen und gegenwärtige Perspektiven, editado por el Institut für Soziologie und Sozialforschung der Carl von Ossietzky-Universität Oldenburg. Opladen: Leske+Budrich, 43-62.

Weber, M. 2008. El sabio y la política. Córdoba: Universidad Nacional de Córdoba, Encuentro Grupo Editor. EP 